\title{
LATIHAN WEIGHT TRAINING DENGAN METODE CIRCUIT TRAINING TERHADAP HYPERTHROPY OTOT
}

\author{
Ardyansyah Arief Budi Utomo ${ }^{1)}$, Ghon Lhisdiantoro ${ }^{2)}$ \\ ${ }^{1}$ Fakultas Ilmu Kesehatan dan Sains, Universitas PGRI Madiun \\ email: ardyansyah@unipma.ac.id \\ ${ }^{2}$ Fakultas Ilmu Kesehatan dan Sains, Universitas PGRI Madiun \\ email: ghon@unipma.ac.id
}

\begin{abstract}
Abstrak
Latihan weight training kini sudah sangat menjamur di masyarakat, namun ada beberapa hal yang perlu diperhatikan dalam melakukan weight training sebagai suatu disiplin ilmu yang harus diimplementasikan untuk menuju kepada suatu tujuan latihan sesuai dengan yang dikehendaki. Metode latihan circuit training salah satunya, metode circuit training adalah suatu metode latihan fisik yang melibatkan latihan kebugaran jasmani dan latihan kekuatan. Metode latihan circuit training sudah teruji dapat meningkatkan daya tahan otot dan kekuatan otot dengan efektif. Circuit training pada weight training juga merupakan penerapan dan kombinasi yang tepat dalam meningkatkan kebugaran, kekuatan, dan massa otot (muscle hyperthropy). Ada beberapa prinsip latihan weight training yang tidak boleh ditinggalkan, karena hal itu merupakan prinsip untuk membangun otot secara tepat dan menghindarkan dari over training.
\end{abstract}

Kata Kunci: Weight Training, Circuit Training, Hyperthropy Otot

\section{PENDAHULUAN}

Latihan dalam terminologi asing sering disebut dengan training, exercise, workout, dan practice. Di dalam Ambarukmi (2007:1), menyebutkan bahwa beberapa ahli mengemukakan pendapatnya tentang pengertian latihan (training) olahraga sebagai berikut: (1) Latihan adalah proses penyempurnaan berolahraga melalui pendekatan ilmiah, khususnya prinsip-prinsip pendidikan, secara teratur dan terencana sehingga mempertinggi kemampuan dan kesiapan olahragawan (Hare, 1982); (2) Latihan adalah program pengembangan atlet untuk bertanding, berupa peningkatan keterampilan dan kapasitas energi (Bompa, 1999:394); (3) Latihan adalah proses yang sistematis untuk meningkatkan kebugaran atlet sesuai cabang olahraga yang dipilih (Thomson, 1993:61).

Dari beberapa pendapat di atas, dapat ditarik kesimpulan bahwa latihan merupakan aktifitas fisik yang dilakukan dengan pendekatan ilmiah dengan proses yang sistematis yang merupakan program pengembangan kemampuan atlet.

Untuk mencapai tujuan tersebut, maka diperlukan teori latihan yang didalamnya terdapat beberapa disiplin ilmu antara lain filsafah, psikologi olahraga, biomekanika, sejarah, gizi olahraga, dan anatomi fisiologi. Adapun sasaran latihan diperlukan sebagai pedoman pelatih maupun atlet dalam menjalankan program latihan, menurut Ambarukmi (2007:2), sasaran latihan tersebut meliputi:

1. Perkembangan Fisik Multilateral

Atlet memerlukan pengembangan fisik secara menyeluruh (multilateral) berupa kebugaran (fitness) sebagai dasar pengembangan aspek lainnya yang diperlukan untuk mendukung prestasinya.

2. Perkembangan Fisik Khusus Cabang Olahraga 
Setiap atlet memerlukan persiapan fisik khusus sesuai cabang olahraganya, mislanya seorang pemain bola voli perlu power otot tungkai yang baik, seorang pesenam memerlukan kelentukan yang sempurna, pemain sepak bola dituntut memiliki kelincahan yang baik, dan sebagainya.

3. Faktor Teknik

Kemampuan biomotor seorang atlet dikembangkan berdasarkan kebutuhan teknik cabang olahraga tertentu untuk meningkatkan efisiensi gerakan, mislanya untuk menguasai teknik jump servis, seorang pemain voli perlu memiliki power tungkai dan keseimbangan tubuh yang baik.

4. Faktor Taktik

Siasat memenangkan pertandingan merupakan bagian dari tujuan latihan dengan mempertimbangkan kemampuan kawan, kekuatan dan kelemahan lawan, dan kondisi lingkungan pada saat itu.

5. Aspek Psikologis

Kematangan psikologis diperlukan untuk mendukung prestasi atlet. Latihan psikologis bertujuan untuk meningkatkan disiplin, semangat, daya juang, rasa percaya diri, dan keberanian.

6. Faktor Kesehatan

Kesehatan merupakan bekal yang perlu dimiliki seorang atlet, sehingga perlu pemerikasaan secara teratur dan perlakuan untuk mempertahankannya.

7. Pencegahan Cedera

Cedera merupakan peristiwa yang paling ditakuti setiap atlet, untuk itu perlu adanya upaya pencegahan cedera melalui peningkatan kelentukan sendi, kelenturan, dan kekuatan otot.

Dari beberapa sasaran latihan di atas, maka dapat dikonklusikan bahwa latihan dengan sasaran yang berbeda, maka perlakuan pada saat latihanpun pasti berbeda, sebagai contoh, seorang atlet binaraga tidak diharuskan mempunyai kelentukan yang sama dengan atlet senam.

Setiap kecabangan olahraga pasti mempunyai target prestasi yang berbeda-beda, atlet sprint 100 meter dituntut mempunyai limit yang sedikit, atlet sepak bola dituntut memasukkan gol ke dalam gawang lawan, dan sejenisnya. Namun hal itu perlu adanya latihan, terutama dalam hal kondisi fisik seperti kekuatan, power, kelentukan, kelincahan, dan sebagainya. Dalam hal kekuatan dan power, tentu saja berkaitan langsung dengan massa otot, secara ilmiah, semakin besar massa otot atlet, maka semakin kuat atlet tersebut melakukan gerakan yang dimaksud. Sebagai contoh, atlet angkat berat dituntut mempunyai kekuatan dan power otot lengan dan dada dalam melakukan bench press, maka yang harus dilakukannya adalah melatih otot lengan dan dada dengan melakukan weight training atau latihan beban. Salah satu indikasi bahwa kekuatan dan power atlet tersebut meningkat ialah ditandai dengan adanya hyperthropy otot lengan dan dada. 


\section{HASIL DAN PEMBAHASAN}

\section{Weight Training}

Weight Training atau latihan beban merupakan jenis latihan untuk meningkatkan kekuatan otot. Ditandai dengan membesarnya massa otot atau disebut hyperthropy. Weight Training dibagi menjadi 2 bentuk latihan, yaitu Free Weight dan Weight Machine. Free Weight adalah bentuk latihan beban yang menggunakan beban bebas biasanya dalam bentuk dumbbell atau barbbell, beban latihan berupa piringan beban ditaruh di ujung bar yang terbuat dari baja (Ambarukmi, 2007:89). Seperti contoh, gerakan biceps curl menggunakan beban dumbbell, gerakan triceps kick back menggunakan dumbbell.

Dalam gambar 1 berikut akan dipaparkan berupa gambar mengenai bentuk free weight dari weight training.

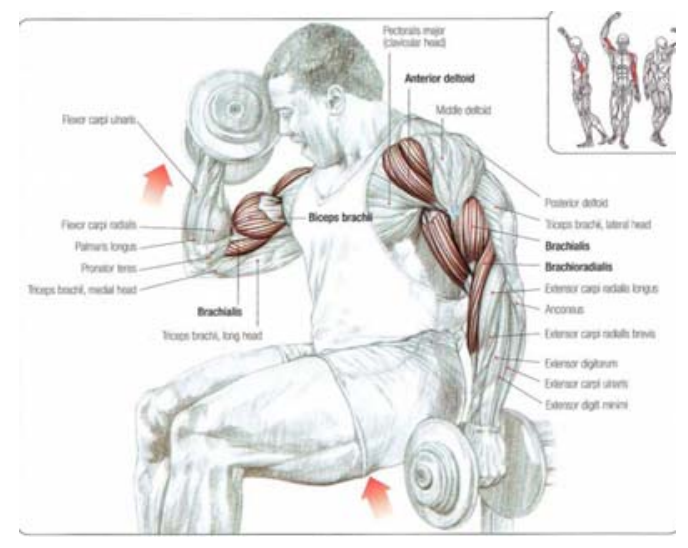

Gambar 1. Free Weight (Biceps Curl)

Sedangkan Weight Machine adalah bentuk latihan beban yang menggunakan bantuan alat katrol atau sejenisnya yang bebannya sudah dijadikan dalam satu tempat dan dapat disesuaikan dengan mudah serta lebih safety dalam penggunaannya. Bentuk latihan yang menggunakan Weight Machine bisa berupa Chest Press Machine, Lat Pull Down, dan masih banyak lagi. Dalam gambar 2 berikut akan dipaparkan berupa gambar mengenai bentuk Weight Machine.

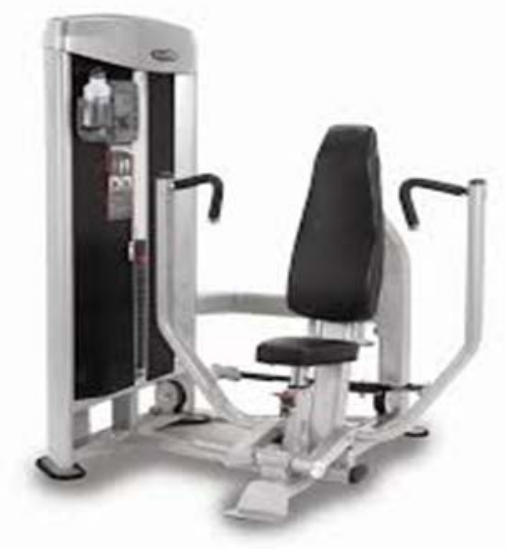

Gambar 2. Weight Machine (Chest Press Machine) 


\section{Circuit Training}

Circuit training atau latihan sirkuit adalah suatu metode latihan fisik yang melibatkan latihan kebugatan jasmani dan latihan kekuatan. Latihan sirkuit merupakan metode latihan yang sudah teruji dan dapat meningkatkan daya tahan otot dan kekuatan otot dengan efektif (Ambarukmi, 2007:102).

Circuit training diperkenalkan pertama kali oleh Morgan dan Admason pada tahun 1959 di Universitas Leeds. Menurut Morgan dan Admason, circuit training merupakan metode untuk mengembangkan kebugaran jasmani secara general atau umum (Bompa, 1999:124). Ciri-ciri circuit training adalah berisi beberapa station exercise atau beberapa pos latihan yang dilakukan secara circle. Pengelompokan circuit training berdasarkan jumlah pos latihannya dibagi menjadi 3, yaitu short exercies (6-9 exercises), medium exercises (9-12 exercises), dan long excersices (12-15 exercises) (Bompa, 1999:124).

Adapun pengaturan latihan jika ingin melakukan metode latihan circuit training antara lain adalah:

a. Atlet boleh memilih jenis latihan dari pos mana saja kemudian pindah ke pos latihan berikutnya, sampai semua pos latihan dikunjungi dan dikerjakan, yang keseluruhannya membentuk circle latihan yang lengkap.

b. Ada waktu maksimal yang menjadi batas waktu penyelesaian satu sirkuit atau jumlah repetisi latihan yang harus diselesaikan pada setiap pos latihan.

c. Pertimbangan yang harus dilakukan ketika hendak melakukan latihan sirkuit antara lain adalah: bentuk latihan, urutan latihan (kaki - lengan - perut - dst), waktu kerja/waktu latihan, dan lamanya istirahat.

Terlepas dari batasan-batasan dan pengaturan pada circuit training, durasi latihan dan boleh jadi beberapa kali akan diulang tergantung dari jumlah pos latihan yang terlibat. Dalam memutuskan jumlah sirkuit, jumlah repetisi per pos, dan beban, maka harus mempertimbangkan level kebugaran dari masing-masing individual atlet.

Berikut akan dipaparkan contoh weight training menggunakan metode circuit training yang mendasarkan pada kebugaran jasmani dan hyperthropy otot:

a. Pos 1 (Bench Press)

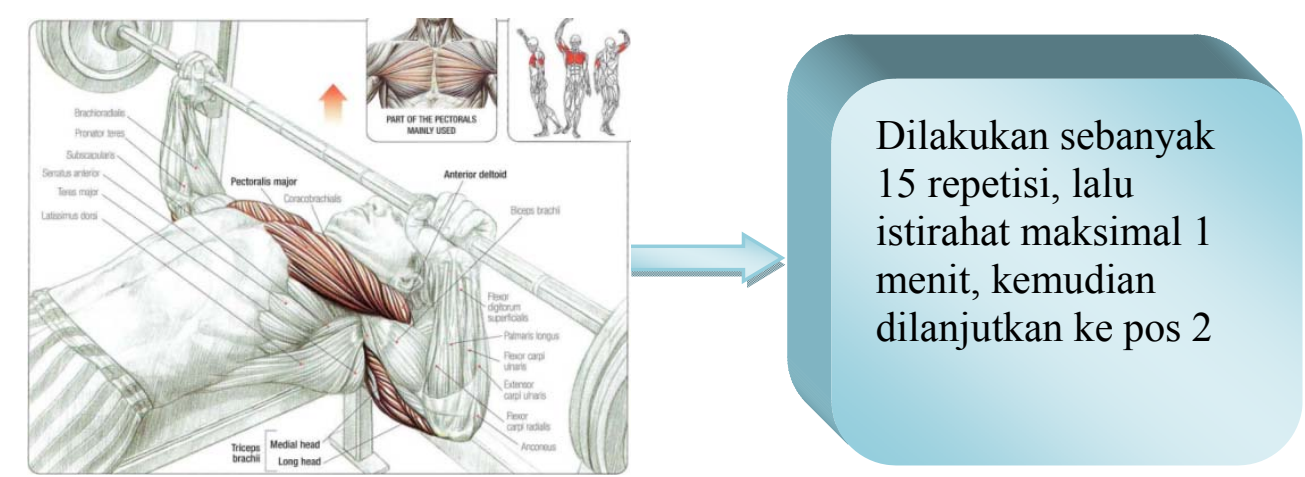

Gambar 3. Bench Press 
b. Pos 2 (Paralel Bar Dips)

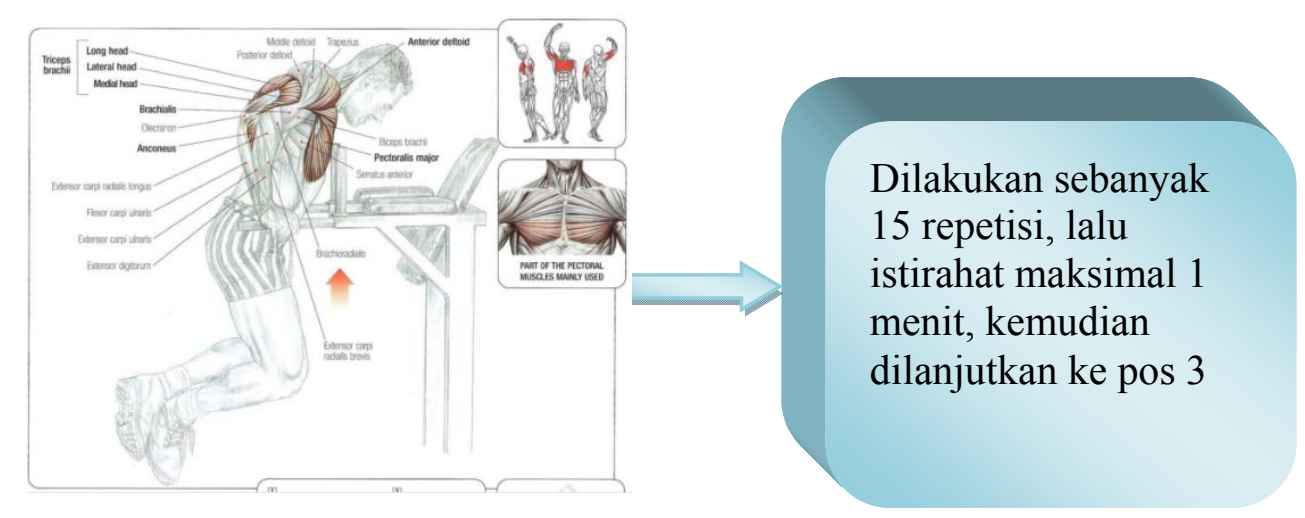

Gambar 4. Paralel Bar Dips

c. Pos 3 (Dumbbell Flys)
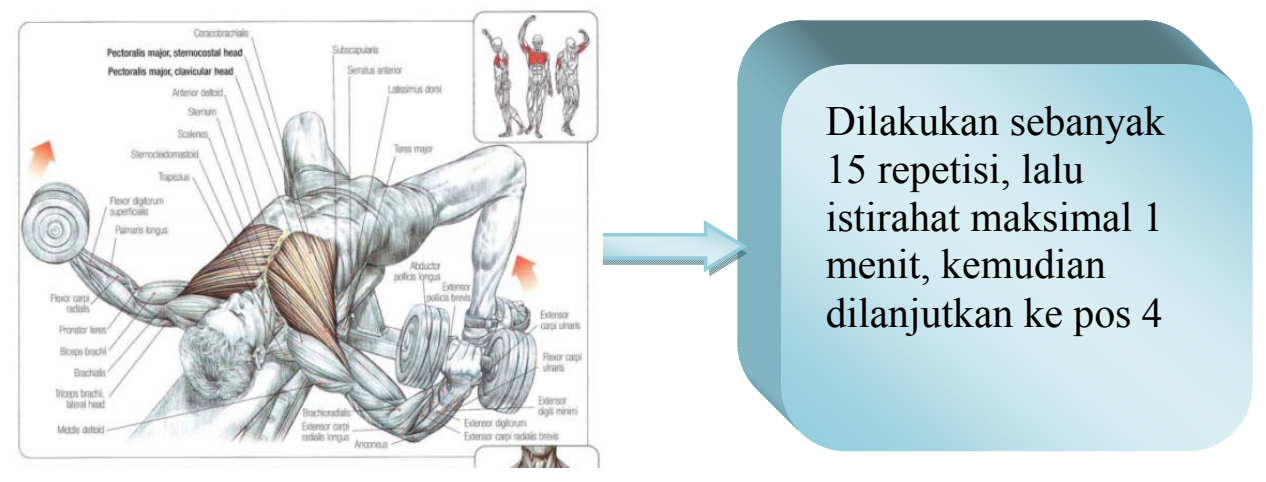

Gambar 5. Dumbbell Flys

d. Pos 4 (Reverse Push Down)

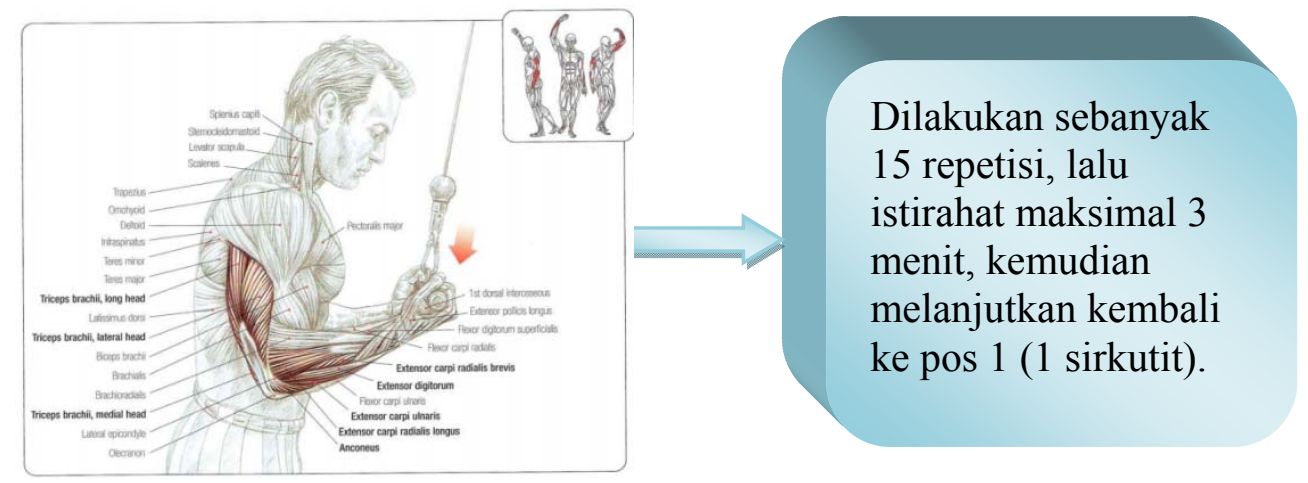

Gambar 6. Reverse Push Down 
Ilustrasi dari latihan di atas akan ditampilkan dalam bentuk gambar sebagai berikut:

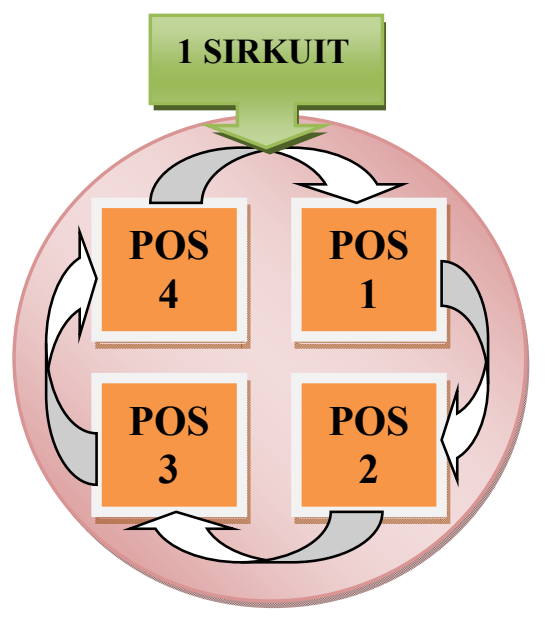

Gambar 7. Circuit Training Record Sheet

Untuk mempermudah pencatatan latihan dalam circuit training, maka dibuatlah Circuit Training Record Sheet sebagai berikut:

Tabel 1. Circuit Training Record Sheet

\begin{tabular}{|c|c|c|c|c|c|c|c|}
\hline \multicolumn{8}{|c|}{ Circuit Training Record Sheet } \\
\hline Nama & \multicolumn{3}{|c|}{ 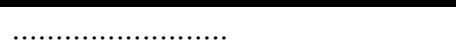 } & HR Min & ........... & \multicolumn{2}{|c|}{....bit/mnt } \\
\hline Umur & \multicolumn{3}{|c|}{.................. Tahun } & $H R \operatorname{Max}$ & ........... & \multicolumn{2}{|c|}{.......bit $/ \mathrm{mnt}$} \\
\hline \multirow{2}{*}{ Pos Latihan } & \multicolumn{7}{|c|}{ Sirkuit } \\
\hline & 1 & 2 & 3 & 4 & 5 & 6 & 7 \\
\hline \multicolumn{8}{|l|}{ Bench Press } \\
\hline \multicolumn{8}{|l|}{ Bar Dips } \\
\hline \multicolumn{8}{|l|}{ Dumbbell Fly } \\
\hline \multicolumn{8}{|l|}{ Reverse Push Down } \\
\hline Catatan: & & & & & & & \\
\hline
\end{tabular}

(Ambarukmi, 2007:106).

\section{Hypertrophy Otot}

Hypertrophy otot adalah pertumbuhan jaringan otot melalui peningkatan ukuran dari unsur jaringan otot, bukan jumlah sel otot. (Bompa, 1999:132). Hypertrophy otot bisa didapatkan dengan cara berlatih mengangkat beban (weight training). Utamanya bagi atlet binaragawan, pembesaran otot sangat diperlukan bagi binaragawan, dengan ukuran otot yang lebih besar, maka atlet dapat meraih prestasi.

Namun tidak semua atlet memerlukan ukuran otot yang terlampau besar, seperti halnya atlet sprint 100 meter tidak akan memerlukan ukuran otot yang terlampau besar, namun untuk menguatkan otot-otot yang notabene dominan pada otot kaki, atlet sprint dapat melatih secukupnya menggunakan weight training. 


\section{SIMPULAN DAN SARAN}

Latihan merupakan satu-satunya cara untuk meraih prestasi bagi seorang atlet. Peranan otot sangat berpengaruh bagi terealisasinya sebuah prestasi atlet, baik dalam hal kekuatan, ketrampilan, kelentukan, semuanya itu menggunakan peran otot. Untuk itu atlet dituntut agar selalu melatih kekuatan otot, sebagai komponen penggerak utama dalam aktifitas.

Salah satu latihan yang mampu dan dikhususkan untuk membesarkan ukuran otot adalah weight training atau latihan beban. Di dalam weight training, terdapat beberapa macam metode latihan, salah satunya adalah metode latihan circuit training. Yang mana metode circuit training termasuk dalam metode yang menghindarkan dari kejenuhan saat berlatih, karena pada penerapannya metode tersebut dilakukan dengan berganti-ganti pos latihan.

Jika weight training dilakukan secara rutin, maka besar kemungkinan ukuran otot akan bertambah. Secara ilmiah, semakin besar ukuran otot, maka semakin kuat pula melakukan suatu gerakan tertentu. Namun, hal ini tidak menjadi tolok ukur sepenuhnya untuk menjadi komponen tercapainya prestasi, karena masih banyak komponen-komponen lainnya yang juga harus dikembangkan dan dilatih oleh atlet seperti kelincahan, koordinasi, kelentukan, ketrampilan, dan lain-lain.

Circuit training (dalam hal ini pada weight traning) merupakan metode latihan yang cukup general, karena melibatkan seluruh bagian otot (tergantung dari isi latihan per posnya).

\section{DAFTAR PUSTAKA}

Ambarukmi, (2007). Pelatihan Pelatih Fisik Level 1. Jakarta: Kementerian Pemuda dan Olahraga Republik Indonesia.

Bompa, Tudor O. (2006). Periodization Training for Sports. Unites States of America: Human Kinetics.

Delavier, Frederic. (2007). Strenght Training Anatomy. Second Edition. Canada: Human Kinetics.

Delavier, Frederic. (2010). Strenght Training Anatomy. Third Edition. Canada: Human Kinetics.

Unesa, (2014). Pedoman penulisan tesis dan disertasi program pasca sarjana. Surabaya: Unesa University Press. 